\title{
Analysis of Subsequent Fractures after Percutaneous Vertebroplasty
}

\author{
Soon Oh Hong ${ }^{1}$, Min Ho Kong ${ }^{1 凶}$, Se Youn Jang ${ }^{1}$, Jung Hee Kim¹, Yoon Ha², Dong Soo Kang ${ }^{1}$, \\ Kwan Young Song 1 \\ 'Department of Neurosurgery, Seoul Medical Center, Seoul, Korea \\ 2Department of Neurosurgery, Spine and Spinal Cord Institute, Severance Hospital, Yonsei University College of Medicine, Seoul, Korea
}

\begin{abstract}
Objective: Percutaneous vertebroplasty (PVP) is a useful treatment to patients with painful osteoporotic vertebral compression fracture (VCF), but long-term studies suggested that PVP could accelerate the failure of adjacent vertebrae after PVP. The authors retrospectively reviewed the cases with PVP and investigated the associated risk factors of new VCF after PVP. Material and Methods: In this retrospective study, total 130 patients who underwent PVP from January 2011 to June 2012 with minimum 12 months follow-up periods were enrolled. New VCFs were diagnosed using radiographical criteria. The causative factors of new VCF, such as age, gender, body weight, height, lumbar spine bone mineral density (BMD), treated vertebral level, pre-existing untreated VCF before treatment, osteoporosis treatment, volume of injected cement, and surgical variables were analyzed. Results: New VCF were observed in 15 cases (11.5\%) among 130 patients with PVP. The common levels of new VCF were L1 (33.0\%) and T12 level (29.2\%). New VCFs were observed more frequently in the adjacent level (9/15 cases) and adjacent level new VCFs were developed earlier than non-adjacent level new VCFs (7.11 \pm 10.40 months vs. $18.66 \pm 22.60$ months, $p=0.039)$. Age, gender, past history, baseline BMD, and T score were not associated with new-onset VCF, but preexisting VCFs history $(p=0.011)$ and larger volume of injected cement $(3.21 \pm 1.66 \mathrm{~mL} \mathrm{Vs} .4 .96 \pm 2.23 \mathrm{~mL}$, $p=0.049$ ) showed significant difference between the cases with and without new VCF. Conclusion: New VCF after PVP was observed in $11.5 \%$ and it seems to be related to adjacent PVP level, larger amount of injected vertebral cement, and the history of preexisting VCFs.
\end{abstract}

Key Words: Vertebroplasty; Osteoporosis; Compression fracture; Adjacent segment disease.

هCorresponding author: Min Ho Kong, Department of Neurosurgery, Seoul Medical Center, 156 Sinnae-ro, Jungrang-gu, Seoul 02053, Korea. Tel: 82-2-2276-7881, Fax: 82-2-2276-8537, E-mail: davidmhkong@gmail.com

\section{INTRODUCTION}

After first report of vertebroplasty procedures by Galibert et al. in $1987^{6,19)}$, percutaneous vertebroplasty (PVP) is a well-established technique for treating osteoporotic compression fractures and an efficient procedure to treat pain due to osteoporotic vertebral compression fracture $(\mathrm{VCF})^{1,3,5-7,9-13,17-20)}$. Recent study reported that overall success rates of PVP as $60 \%$ to $90 \%$ with providing immediate significant pain relief ${ }^{17)}$, restoring the patients' quality of life, and shortening the hospitalization days ${ }^{133}$. But long-term studies showed different opinion with suggesting possible accelerated failure rate in the adjacent vertebral body after PVP. The new subsequent fractures were seldom observed after PVP, although it is not clear whether such fractures are procedure-related complication or the natural course of osteoporosis. Although, some study suggested the strong association risks in women with preexisting vertebral fractures as ap- proximately 4-times greater risk of subsequent vertebral fractures than those without prior fractures ${ }^{8)}$, the potentially important covariates on new subsequent fractures risk in cemented vertebrae has not been well investigated yet. Biomechanical and clinical studies suggest an increased risk ${ }^{2,14}$, but compelling data have not yet been precisely explained this difficult issue.

Herein, the authors investigated the risk factors related to new subsequent VCFs after vertebroplasty and evaluated the influence of PVP on the adjacent and nonadjacent levels.

\section{MATERIAL AND METHODS}

\section{Patients population}

A retrospective review of charts and radiographs of all consecutive patients who underwent vertebroplasty at the single center was done from January 2010 to June 2011. Total 130 patients were included in this study. 
The indications for PVP were intense focal back pain using visual analog scale (VAS) of more than 5, progressive kyphosis, and failure of conservative medical therapy in patients who had worn an orthosis for at least 2 weeks before surgical intervention. Plain X-ray films were obtained routinely at 1 and 3 months postoperatively during follow-up period or if they developed new onset or worsening of back pain. Exclusion criteria in this study included a history of stroke, senile dementia, major medical diseases requiring intensive treatment including other bone disease. Patients with spinal tumor or infection within the vertebral body were also excluded. Laboratory and biochemical markers were used for exclusion of spinal tumor or infectious disease.

Detail informations were obtained from review of medical records and operation reports with medical history. Also this retrospective study was approved by the Institutional Review Board. All the procedures and patient information were permitted by participating individuals with written informed consent.

\section{Surgical technique of PVP}

Percutaneous vertebroplasty was performed under local anesthesia with usual maneuver as described below. The patient was positioned in prone, and the fracture level was checked using C-arm fluoroscopic guidance. The entry points overlying the pedicles were localized. The midline of the transverse process and the pedicles are identified and marked under fluoroscopy. Under anterior-posterior and lateral fluoroscopy, the guide-wire is inserted until the tip of wire docks on the vertebral body, then advanced to $50-70 \%$ of the vertebral body after trajectory confirmation. After the placement of the guide-wire is confirmed, the guide-wire is replaced with the working cannlua. The tip was placed close to the midline in the lateral view.

We used standard Polymethyl methacrylate (PMMA) mixture consisting of one package of Vetebroplastic cement ${ }^{\mathrm{TM}}$ (Depuy CMW, Blackpool, UK) for visual delivery into the vertebral body.
The cement then was allowed to polymerize until it had a liquid consistency for controlled injection. The mixture was slowly and steadily injected into the vertebral bodies. Continuous fluoroscopic monitoring during injection was undertaken to prevent cement leakage into the spinal canal. The injection was stopped when the syringe compressor encountered strong resistance.

\section{Outcome measurement}

The patients' degree of pain was evaluated by VAS score. VAS score was indicated on a 10 -point scale raging from 0 (no pain) to 10 (worst pain in the patient's life). Effective improvement after procedure was defined as decrease of score at least 3 (VAS score $\geq 3$ ) in our study and is achieved in more than $90 \%$ of follow-up reviewed individuals after vertebra augmentation. Moderate improvement was defined as change of score less than 3 (VAS score $\leq 3$ ) was evaluated.

\section{New subsequent fractures}

A patient was considered to have a symptomatic subsequent fracture when all four of the following criteria were met : 1) definite decreased vertebral body height on simple radiographs compared to previous post-vertebroplasty images, 2) acute aggravated back pain and tenderness some time period after previous vertebroplasty procedure, 3 ) identified pain with matched anatomical level in radiographic findings, and 4) MRI revealed bone marrow change with low signal intensity on $\mathrm{T} 1$ weighted images or bone scan revealed the hot uptake corresponding to the radiographic findings. In subsequent VCFs, the subjectively painful vertebra was assessed objectively by a combination of local tenderness at the fracture site on the physical examination, the typical appearance of this fracture on simple X-ray evaluation and bone marrow change and edema which was evaluated by $\mathrm{T} 1$ weighted magnetic resonance image or hot uptake findings on the bone scan evaluation radiographically.
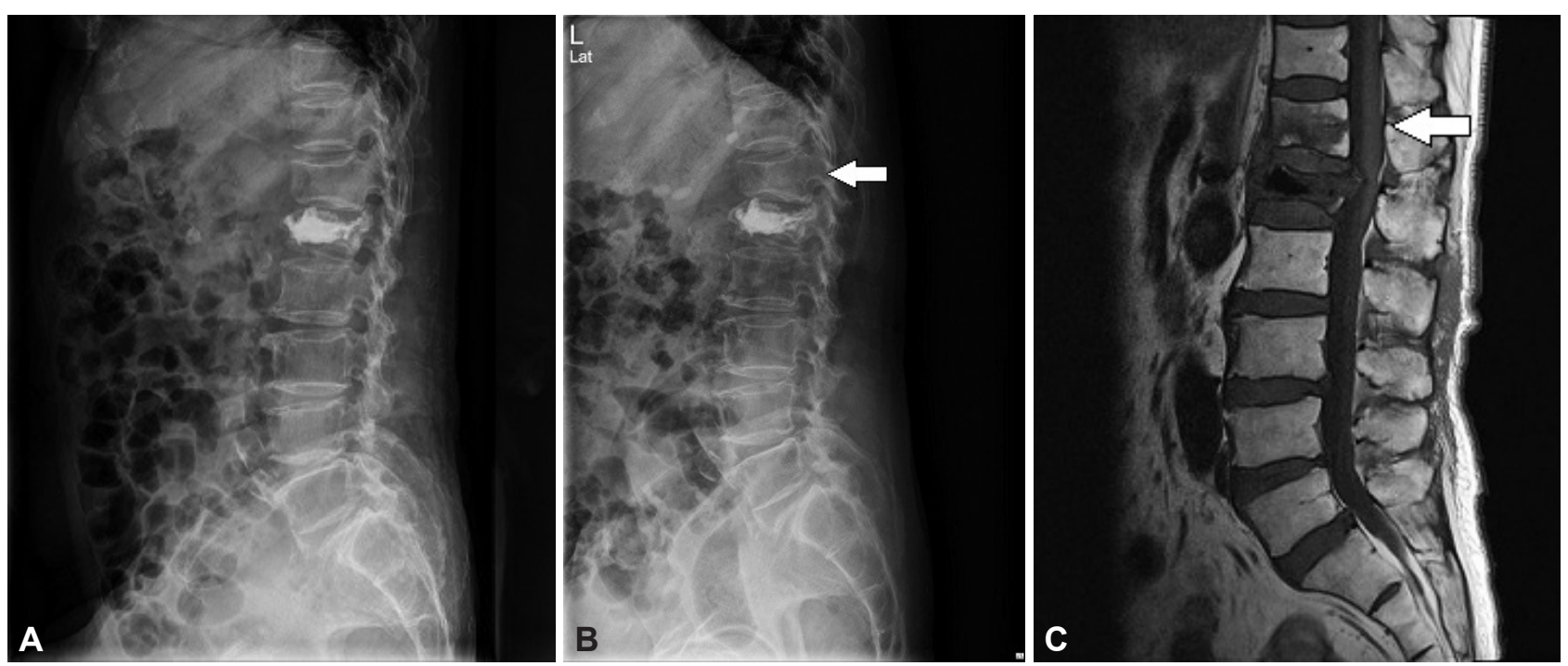

Fig. 1. Adjacent compression fracture. Simple plain X-ray (A) obtained in a 79-year-old woman with a history of acute L1 VCF. New compression fracture that occurs immediately one level above (T12) (B) (arrow) to a augmented fractured vertebra on plain radiograph. She developed newly onset low back pain corresponding low signal on T12 on the MRI image (C) adjacent to previous PVP 1 month later. 

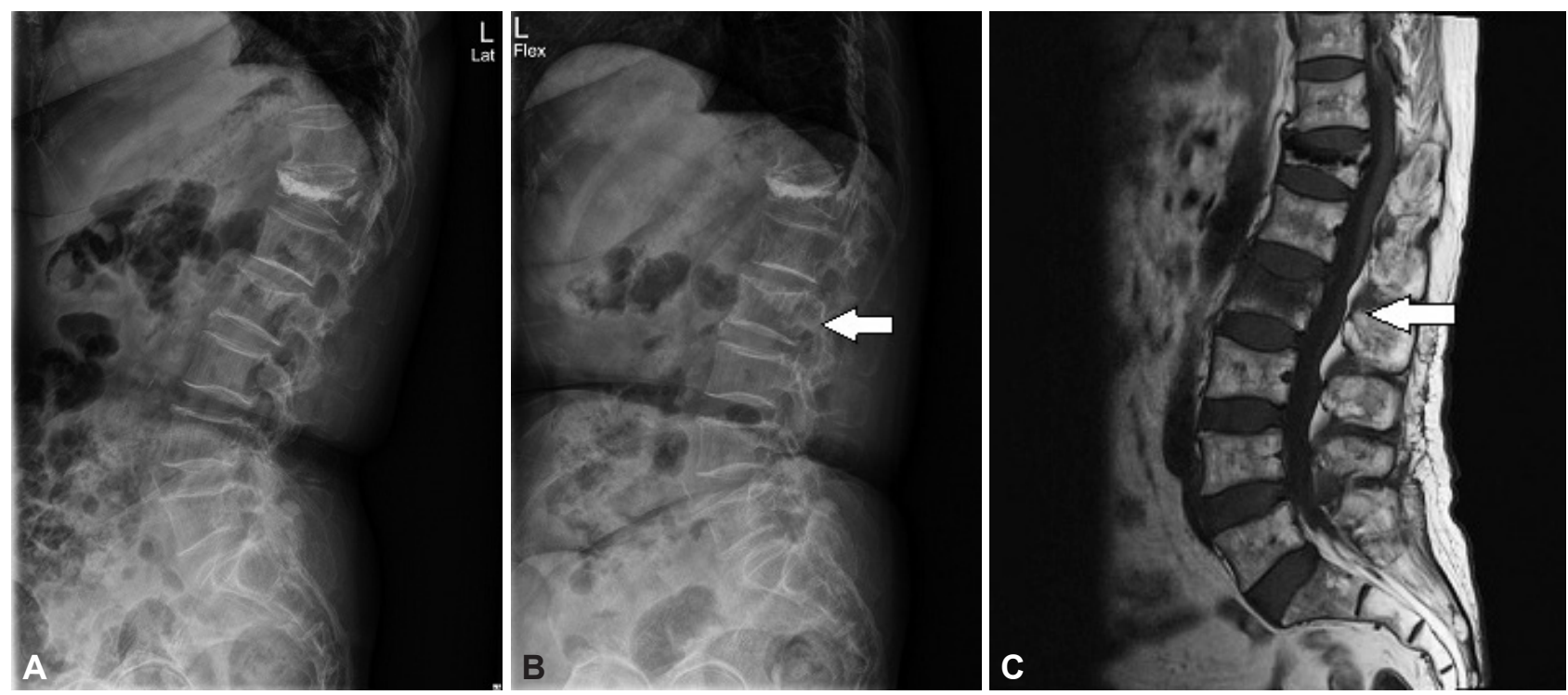

Fig. 2. Remote nonadjacent compression fracture. The 61-old-year old woman underwent T12 vertebral augmentation which displayed at plain radiography (A). She developed new back pain after successful vertebroplasty at T12. A new fracture is visible at L2 in the follow-up radiographs $(B)$. T1 weighted MRI presents low signal at $L 2(C)$ which is compatible with clinical symptoms.

Adjacent compression fracture is defined as a new compression fracture that occurs immediately rostral or caudal to a previously augmented fractured vertebra (Fig. 1). Besides remote compression fracture that occurs far distant or distal to a previously augmented vertebra is defined as nonadjacent compression fracture (Fig. 2). There should be at least one intervening vertebra between the new compromising vertebra and the previous treated one.

\section{Data analysis \& Statistical analysis}

We assigned serial numbers to consecutive 130 patients experienced osteoporotic compression fractures and had PVP. Under informed consent, patients' data including age, gender, the period between prior and subsequent VCFs, and the location of fractured vertebra were recorded.

Patient characteristics were summarized using descriptive statistics. Database was created containing patient age, gender, height, weight, anti-osteoporotic medication history, BMD value, T-score, newly onset vertebral compression fracture, preexisting untreated compression fracture, and time interval between new compression fracture and previous one as well as amount of injected PMMA. Additionally, uni/bilateral approach methods also included.

All the data were analyzed using paired t-test and chi-square statistical analysis as appropriate using SPSS software. A $p$ value defined as less than 0.05 was chosen to determine statistical significance.

\section{RESULTS}

\section{Characteristics of the patients}

The 130 patients had a mean age of 71.9 years (range, 37-93). Among them, $72.3 \%$ were woman ( 94 female and 36 male). To

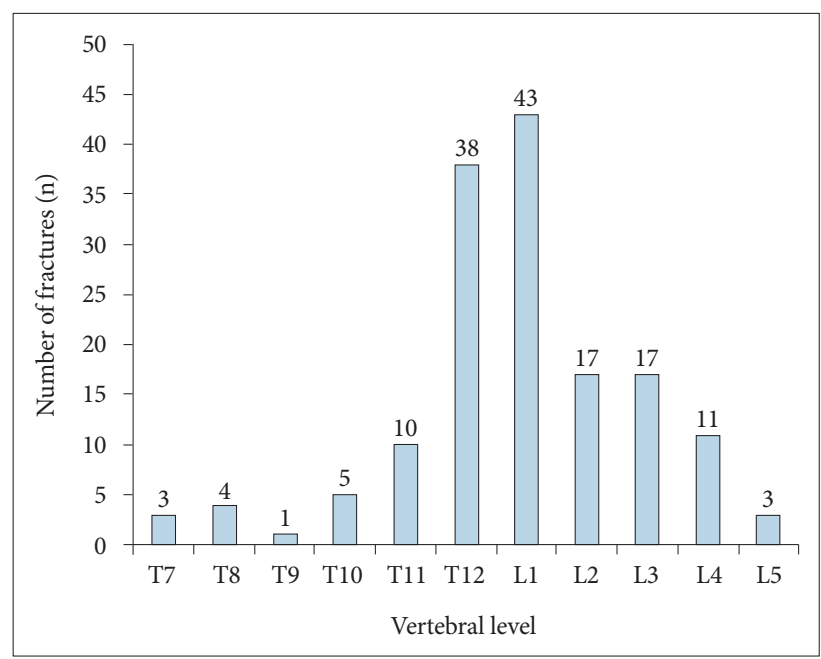

Fig. 3. The distribution of fractures at each vertebral level. T12 and L1 were the common sites of fractures treated initially, followed by L2, L3.

alleviate persistent pain, limitation of activity and shorten hospital day, 139 consecutive osteoporotic VCF patients underwent PVP during the follow-ups. Nine patients were excluded in this study because known multiple myeloma $(n=1)$, known spinal metastases $(\mathrm{n}=1)$, inflammation of within the other vertebral body $(n=1)$, and relatively short follow-up period $(n=6)$. In the distribution of fractures at each vertebral level, L1 (33.0\%) and T12 (29.2\%) were the common sites of fractures treated initially, followed by L2, L3 (Fig. 3).

\section{Pain improvement after PVP}

Effective improvements after procedures is achieved in more than $80 \%$ (104 patients) of follow-up periods after vertebra augmentation. Of 130 participants, initial mean VAS score was $7.80 \pm 0.63$ before vertebroplasty and then after PVP, mean VAS 
score was significantly improved to $3.96 \pm 1.37$. Eighteen patients (14\%) of moderate improvements and $6 \%$ (8 patients) of minimal change of VAS score were observed.

\section{New subsequent VCFs after PVP}

The demographics of patients with new compression fractures after PVP compared with those with no new compression frac-

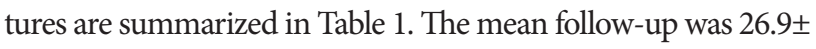
12.4 months (range, 12-48 months). New VCFs develops generally in 6 months after first compression fractures (Fig. 4). The

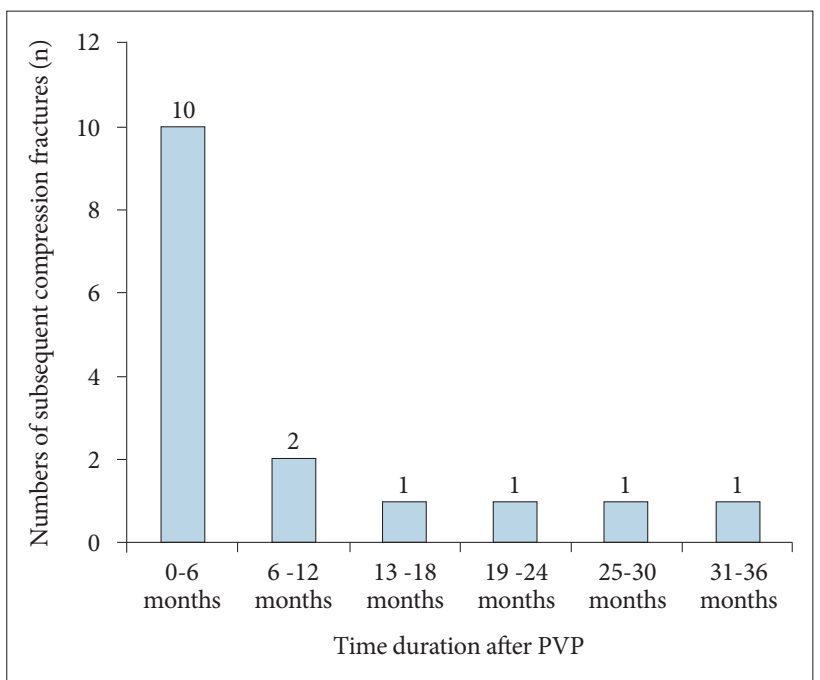

Fig. 4. Time duration of subsequent new compression fracture after PVP. The mean time duration of subsequent new compression fracture after vertebral body augmentation is mostly identified within first 6 months (10 out of 15 patients), and 6-12 months as following (2 out of 15 patients). After this 2 periods of time interval, incidence of subsequent fracture is relatively rare and similar compared to initial $0-6$ and $6-12$ months. mean age of patients with occurrence of new compression fracture was not statistically significant $(71.52 \pm 12.23$ years and $74.93 \pm$ 8.52 years, $p>0.05)$. Mean amount of cement injection per vertebral body was $3.58 \mathrm{~mL}$ for the vertebroplasty. Newly onset subsequent VCFs occur at $11.54 \%(15 / 130)$ of patients after vertebroplasty. Most of the vertebroplasty procedures required bilateral augmentation rather than unilateral procedures. There were 2 cement extravasation resulting in transient radiculopathy, but no myelopathy in PVP.

It is statistically significant that more amount of PMMA injected patients had higher incidence of new subsequent VCFs. Mean volume of PMMA in patients with occurrence of new VCFs were $4.96 \pm 2.23 \mathrm{~mL}$ and that of patients who had no new subsequent VCFs was $3.21 \pm 1.66 \mathrm{~mL}(p=0.049)$.

\section{Risk factors of new compression fractures}

Various factors including age, gender, BMD, and pre-existing vertebral compression fractures, amount of cemented polymethyl methacrylate, and anti-osteoporotic treatment were investigated in total populations between new compression fractures after PVP and those with no new compression fractures. The gender, age, body-mass index, history of tobacco use, history of any steroid use, location of fracture, and number of initial fracture levels were not found to have correlation with risk of subsequent fracture (Table 1). In the group with no new VCFs, the mean lumbar spine T-score, calculated from 115 (88.46\%) patients with available baseline lumbar spine BMD values, was -2.598. In the group with NCFs, the mean lumbar spine $\mathrm{T}$ score, calculated from 15 (11.54\%) patients with baseline lumbar spine BMD values, was -2.577 . The T-score and $B M D$ value $\left(\mathrm{g} / \mathrm{cm}^{2}\right)$ are not significantly different between two groups. The

Table 1. Demographics of patients with new VCFs compared with those without new VCFs

\begin{tabular}{|c|c|c|c|}
\hline & Without new VCFs & With new VCFs & $p$ value \\
\hline Total patients $(\mathrm{n}=130)$ & $115(88.46 \%)$ & $15(11.54 \%)$ & \\
\hline Gender (male/female) & $33: 82$ & $3: 12$ & 0.231 \\
\hline Age (yr) & $71.52 \pm 12.23$ & $74.93 \pm 8.52$ & 0.252 \\
\hline \multicolumn{4}{|l|}{ History } \\
\hline Tobacco use & $5(4.3 \%)$ & $1(6.67 \%)$ & 0.156 \\
\hline NSAIDS use & $110(95.6 \%)$ & $15(100 \%)$ & 0.180 \\
\hline Steroid use & $5(4.34 \%)$ & $1(6.67 \%)$ & 0.337 \\
\hline Other malignacy & $6(5.2 \%)$ & $2(13.3 \%)$ & 0.135 \\
\hline \multicolumn{4}{|l|}{ Osteoporotic spine } \\
\hline $\operatorname{BMD}\left(\mathrm{L} 1-4, \mathrm{~g} / \mathrm{cm}^{2}\right)$ & $0.713 \pm 0.1498$ & $0.703 \pm 0.150$ & 0.864 \\
\hline BMD (T score) & $-2.598 \pm 1.295$ & $-2.577 \pm 1.294$ & 0.709 \\
\hline Anti-osteoporotic medication & $74(64.3 \%)$ & $10(66.7 \%)$ & 0.854 \\
\hline \multicolumn{4}{|l|}{ Preexisting VCFs } \\
\hline 0 & 57 & 2 & \multirow{2}{*}{0.011} \\
\hline 1 & 30 & 9 & \\
\hline 2 or more & 28 & 4 & \\
\hline Trauma history (2nd fracture) & $3(2.61 \%)$ & $1(6.67 \%)$ & 0.151 \\
\hline \multicolumn{4}{|l|}{ Procedure related factor } \\
\hline Unilateral/bilateral & $34 / 81$ & $4 / 11$ & 0.816 \\
\hline Amount of cemented PMMA (mL) & $3.21 \pm 1.66$ & $4.96 \pm 2.23$ & 0.049 \\
\hline
\end{tabular}


Table 2. Characteristics of comparison between adjacent and nonadjacent to cemented vertebrae of patients with new VCFs

\begin{tabular}{|c|c|c|c|}
\hline New VCFs & Adjacent & Nonadjacent & $p$ value \\
\hline Number of patients $(\mathrm{n}=15)$ & $9(60 \%)$ & $6(40 \%)$ & \\
\hline Gender (men/women) & $1: 8(88.9 \%)$ & $2: 4(66.7 \%)$ & 0.034 \\
\hline Age $(y r) \pm S D$ & $73.89 \pm 8.21$ & $76.5 \pm 8.23$ & 0.580 \\
\hline $\begin{array}{l}\text { Mean time to subsequent } \\
\text { VCFs (months) }\end{array}$ & $7.11 \pm 10.40$ & $18.66 \pm 22.60$ & 0.039 \\
\hline \multicolumn{4}{|l|}{ History } \\
\hline Tobacco use & 0 & 1 & 0.040 \\
\hline NASIDs use & 9 & 6 & 1.000 \\
\hline Steroid use & 0 & 0 & 1.000 \\
\hline Other malignancy & 1 & 1 & 0.179 \\
\hline \multicolumn{4}{|l|}{ Osteoporotic factor } \\
\hline Baseline BMD (L1-4, $\left.\mathrm{g} / \mathrm{cm}^{2}\right)$ & $0.71 \pm 0.15$ & $0.69 \pm 0.16$ & 0.336 \\
\hline T-score & $-3.64 \pm 0.05$ & $-2.79 \pm 1.34$ & 0.279 \\
\hline Anti-osteoporotic medication & $6(66.7 \%)$ & $3(50.0 \%)$ & 0.756 \\
\hline \multicolumn{4}{|l|}{ Procedure related factor } \\
\hline Approach unilateral/bilateral & $4 / 5$ & $1 / 5$ & 0.263 \\
\hline $\begin{array}{l}\text { Amount of cemented PMMA } \\
(\mathrm{mL})\end{array}$ & $4.50 \pm 1.63$ & $4.33 \pm 0.47$ & 0.858 \\
\hline \multicolumn{4}{|l|}{ Preexisting VCFs } \\
\hline 1 & 5 & 3 & \multirow{2}{*}{0.196} \\
\hline 2 or more & 4 & 3 & \\
\hline
\end{tabular}

injected amount of PMMA was 3.21 \pm 1.66 (range : $2-12 \mathrm{~mL}$ ) in the group with no new VCFs and $4.96 \pm 2.33$ (range : $2-11 \mathrm{~mL}$ ) in the group with VCFs and it was statistically significant ( $p=$ 0.049). Anti-osteoporotic treatment was not statistically significant between new subsequent VCFs and non-new subsequent VCFs $(p=0.07)$.

\section{Adjacent new compression fractures}

In 130 patients (138 vertebrae), 60.0\% (9/15) of new compression fractures after vertebroplasty were adjacent compression fractures (Table 2). Of the 15 subsequent fractures, there were 9 at the adjacent-above levels and 6 at remote levels. Adjacent fractures occurred much earlier than the occurrence of nonadjacent fractures $(7.11 \pm 10.40$ months vs. $18.66 \pm 22.60$ months). This mean time interval of adjacent VCFs after initial vertebroplasty is shorter compared to duration of nonadjacent VCFs after initial vertebroplasty ( $p=0.039)$. The incidence of new VCFs after vertebroplasy is more frequent and much sooner in adjacent level whichs is statistically significant $(p=0.039)$.

Age, BMD and amount of cemented polymethyl methacrylate were not statistically different between patients who had adjacent level new subsequent VCF and patients who had no nonadjacent level new subsequent VCF except gender. The incidence of adjacent subsequent compression fracture is higher in female patients with statistical significance $(p=0.034)$. The amount of cemented polymethyl methacrylate itself was not statistically significant between adjacent and non-adjacent level VCFs (4.50 \pm $1.63 \mathrm{~mL}$ and $4.33 \pm 0.47 \mathrm{~mL}, p=0.858$ ). There is no statistical significance of adjacent or non-adjacent subsequent compression fracture with use of tobacco, any steroid or non-steroid medication and history of other bone disease in this study. Number of pre-existing vertebral compression fracture has no statistical significance between adjacent and non-adjacent fracture $(p=0.196)$.

\section{DISCUSSION}

VCFs are a common debilitating complication of osteoporosis. This disorder is more than a burden to society in terms of economic and limited activity ${ }^{13)}$. The spine is especially vulnerable to osteoporosis, resulting in more than 700000 VCFs occurring annually in America. Furthermore, there is a $24 \%$ to $34 \%$ increased mortality compared with age-matched adults after a $\mathrm{VCF}^{6}$.

Most fractures heal within a few weeks or months. About one-third of patients continue to experience pain that does not respond to conservative therapy. Vertebral augmentation with PMMA such as PVP is used primarily for osteoporotic compression fractures, osteolytic metastasis and myeloma, and painful and aggressive hemangioma ${ }^{17)}$. Pain likely initiates in intraosseous or periosteal nerves aggravated by motion at the fracture site. PVP is highly effective in relieving the pain associated with vertebral compression fractures. This analgesic effect is long-lasting and it has been hypothesized that the origin of pain relief resulting from the procedure may be a thermal or chemical effect. Additionally, other research suggests a mechanical mechanism $^{7)}$ which restoring strength of a vertebral body may prevent additional collapse, thereby relieving pain and enhancing stability that promotes fracture healing.

Previous studies ${ }^{1,7,11,12,18,19)}$ have suggested a relationship between vertebroplasty and subsequent fracture. The occurrence of VCFs after vertebroplasy has been investigated recently, and the reported incidence of new VCFs after vertebroplasty ranges from 12 to $52 \%{ }^{1,5)}$. The literature on subsequent fractures after kyphoplasty describes a 3 to $29 \%$ rate of subsequent fractures. The present study also reports a $11.54 \%$ (15/115) rate of subsequent fractures over 12 months minimum follow-up period after vertebroplasty.

In the literature, generally new VCFs occurred within 3 months after vertebroplasty and another presentation describes the mean time to new subsequent fractures of 10.6 months. In our report, after PVP procedures as management for VCFs, time to occur new VCFs was most common in the period of between first 6 months after that. This results suggest that after PVP, the patients should be cautious to prevent new VCFs and keep the regular follow up within 12 months.

The location of subsequent fractures will be remote levels or adjacent levels. Many studies report suggest that $41-69 \%$ of new VCFs were adjacent to the treated vertebrae ${ }^{10)}$. There appears to be an increased incidence of adjacent-level fractures after PMMA vertebral body augmentation procedures. In our study, the adjacent $(60.0 \%)$ fractures of the new VCF (9/15) more frequently occurred than nonadjacent level. 
Many studies ${ }^{18-20)}$ reported that following vertebroplasty, patients are at increased risk of new-onset adjacent-level fractures. When these fractures develop, they occur sooner than nonadjacent level fractures. In this present study, the mean time to subsequent fractures was shorter in adjacent level than remote level. The development subsequent adjacent level fractures was much sooner than nonadjacent fractures $(7.1 \pm 10.41$ months vs. 17.2 \pm 25.68 months). It can explain that adjacent level is more susceptible to have fractures than remote level during the time progression.

Natural history data suggest that the incidence of subsequent VCFs after experiencing an osteoporotic vertebral compression fracture is $19.2 \%$ when no surgical intervention is performed ${ }^{4)}$. The local and remote effect of vertebroplasty about subsequent VCFs has been analyzed ${ }^{6}$ and mechanism of frequent adjacent vertebral body fractures after PVP has to be documented through various biomechanical studies ${ }^{19}$. Cement augmentation was found to restore strength of the treated vertebra but clearly altered the load transfer in the adjacent vertebra ${ }^{5}$. The percentile change in the maximum principal strain of the adjacent vertebra was 18\% increased in the inferior endplate in flexion with bipedicular filling with PMMA and $11 \%$ increased with unipedicular filling compared with the untreated state ${ }^{14)}$. This helps explain the high incidence of adjacent-level fractures seen in the present study. Another study suggested that the implantation of PMMA into the target vertebral body theoretically increases the strength of the vertebral body in an osteoporotic spine, which may exaggerate force transmission to the remote or adjacent level vertebral bodies, thereby predisposing those levels to future fractures. These data possibly related to an increase in the stiffness of treated vertebra ${ }^{11,14,20)}$. The mechanism underlying this increase seems to stem from excessive cement rigidity ${ }^{19)}$ which reduces local spinal joint flexibility. In other words, acute changes in stiffness may provoke fractures at adjacent levels. These results suggest that either vertebroplasty damages adjacent vertebrae or that vertebroplasty is usually done in a part of the spine that is already weakened, such that adjacent vertebra were more likely to fail even if the vertebroplasty procedure had not been done ${ }^{3)}$.

Kyphotic deformity, result from compression fractures, may lead to facet joint contracture and facet arthritis and accelerate the degeneration at the cranial adjacent level ${ }^{1,15,16)}$. Kyphotic deformity may be a contributor to adjacent level fracture, but it is difficult to proven in the retrospective study. It is widely accepted that maintenance of physiologic spinal alignment is important to minimize the acceleration of degenerative change at the adjacent level.

The occurrence of new VCFs after vertebroplasy has been hypothesized due to altered biomechanics in the treated area of the spine. Specific cadaver study ${ }^{2}$ demonstrated that unusual increases in strength and stiffness influence intervertebral load transfer, especially in the vertebrae immediately above or below the augmented structures ${ }^{14)}$. Similar with this laboratory results, this present study demonstrated that according to the amount of injected PMMA and its distribution, incidence of new subsequent fracture was significantly different. This present study showed that as more amount of PMMA injected, new VCFs is more frequent and especially the adjacent vertebral fracture. These results support that the alteration of biomechanics by PMMA might be responsible for these difference.

Fribourg et al. ${ }^{5}$ reported through the cohort study that VCFs following PVP was clearly at high risk for subsequent fractures because of their age, poor bone quality, and history for previous fracture. In other study, a BMD T-score of -2.2 or less at any vertebra from T10 to L3 is significantly predictive of subsequent fracture in that vertebra ${ }^{20}$. Klotzbuecher et al. ${ }^{8)}$ reported that postmenopausal women with pre-existing VCFs had 2.0 times the risk of subsequent fracture compared with women without prior fracture. The current study showed that pre-exiting VCFs increased the occurrence of new VCFs. The patients with a low BMI are at higher risk of subsequent VCFs of the spine is generally accepted ${ }^{9}$. It was postulated that lower BMI may be associated with weaker vertebra, which is subject to the direct effect of adjacent vertebral augmentation. According to these results, neurosurgical clinicians should be alerted of a higher risk of subsequent fracture after vertebral augmentation that has a T-score value of -2.2 or less or low BMI or postmenopausal women with pre-existing VCFs.

Besides, many procedure related factors including the cement volume and intradiscal cement leakage were discussed with the results that they might increase the stress to the adjacent vertebrae $^{1)}$. The current study showed that the cement volume significantly influenced the occurrence of new VCFs, even though it did not show theirs significant differences between adjacent levels and nonadjacent levels. Especially, because cement leakage into the disk raises the risk of new VCFs in the adjacent vertebrae, the operator needs to be cautious to prevent it during PVP.

Some limitations of the present study were revealed. Firstly, this has not many population in order to account for more specific risk factors of new subsequent VCFs. In the future, a large population with well designed study should be needed for long term follow up period. Secondly, this present study was related to the retrospective design. This limitation had difficulty in time setting of follow up study including BMD or simple X-ray. Furthermore, the authors need to be included more specific data such as level-specific BMD T-scores, intradical cement leakage, or local kypohtic angle parameters which should be investigated in the future study.

\section{CONCLUSION}

This study demonstrated a significant rate (11.5\%) of subsequent fractures after PVP. Most of these subsequent fractures occur at adjacent levels within 6 months of the procedure which supports the hypothesis that cement augmentation places additional stress on adjacent levels. Patients with increase in new 
onset or progressive symptoms after PVP should be evaluated carefully to suspect subsequent adjacent VCFs.

\section{REFERENCES}

1. Ahn Y, Lee JH, Lee HY, Lee SH, Keem SH : Predictive factors for subsequent vertebral fracture after percutanous vertebroplasty. J Neurosurg Spine 9: 129 -136, 2008

2. Belkoff SM, Mathis JM, Jasper LE, Deramond H : The biomechanics of verterbroplasty : the effect of cement volume on mechanical behavior. Spine (Phila Pa 1976) 26 : 1537-1541, 2001

3. Eichler MC, Spross C, Ewers A, Mayer R, Külling FA : Prophylactic adjacent-segment vertebroplasty following kyphoplasty for a single osteoporotic vertebral fracture and the risk of adjacent fracture. J Neurosurg Spine 2 $: 1-7,2016$

4. Frankel BM, Monroe T, Wang C : Percutaneous vertebral augmentation : an elevation in adjacent-level fracture risk in kyphoplasty as compared with vertebroplasty. The Spinal Journal 7 : 575-582, 2007

5. Fribourg D, Tang C, Sra P, Delamarter R, Bae H : Incidence of subsequent vertebral fracture after kyphoplasty. Spine (Phila Pa 1976) 29 : 2270-2276, 2004

6. Harrop JS, Prpa B, Reinhardt MK, Lieberman I : Primary and secondary osteoporosis' incidence of subsequent vertebral compression fractures after kyphoplasty. Spine (Phila Pa 1976) 29 : 2120-2125, 2004

7. Kim HW, Song JW, Kwon A, Kim IH : Extreme multi-level percutaneous vertebroplasty for newly developed multiple adjacent compression fractures. J Korean Neurosurg Soc 45 : 378-380, 2009

8. Klotzbuecher CM, Ross PD, Landsman PB, Abbott TA, Merger M : Patients with prior fractures have an increased risk of future fractures : a summary of the literature and statistical synthesis. J Bone Miner Res 15 : $721-739,2000$

9. Lin CC, Chen IH, Yen PS, Chen DC, Hsu SH, Kwong ST, et al. : Repeat percutaneous vertebroplasty at cemented vertebra with fluid sign and recurrent pain. Interv Neuroradiol 14 (Suppl 2) : 85-90. 2008

10. Lin WC, Cheng TT, Lee YC, Wang TN, Cheng YF, Lui CC, et al. : New vertebral osteoporotic compression fractures after percutaneous vertebroplasty : retrospective analysis of risk factors. J Vasc Interv Radiol 19 : 225232,2008

11. Nagaraja S, Awada HK, Dreher ML, Supta S, Miller SW : Vertebroplasty increases compression of adjacent IVDs and vertebrae in osteoporotic spines. The Spine Journal 13 : 1872-1880, 2013

12. Nieuwenhuijse MJ, Putter H, van Erkel AR, Kijkstra PDS : New vertebral fractures after percutaneous vertebroplasty for painful osteoporotic vertebral compression fractures. Radiology 266 : 862-870, 2013

13. Park JW, Kong MH, Lee SK, Song KY, Kang DS : Improved quality of life after percutaneous vertebroplasty for osteoporotic vertebral body compression fractures in the elderly. J Korean Neurosurg Soc 34 : 560-564, 2003

14. Polikeit A, Nolte LP, Ferguson SJ : The effect of cement augmentation on the load transfer in an osteoporotic functional spinal unit; finite-element analysis. Spine (Phila Pa 1976) 28 : 991-996, 2003

15. Pradhan BB, Bae HW, Kropf MA, Patel VV, Delamarter RB : Kyphoplasty reduction of osteoporotic vertebral compression fractures : correction of local kyphosis versus overall sagittal alignment. Spine (Phila Pa 1976) 31 : 435-441, 2006

16. Rohlmann A, Zander T, Bergmann : Spinal loads after osteoporotic vertebral fractures treated by vertebroplasty or kyphoplasty. Eur Spine J 15 : 1255-1264, 2006

17. Ryu KS, Park CK : The prognostic factors influencing on the therapeutic effect of percutaneous vertebroplasty in treating osteoporotic vertebral compression fractures. J Korean Neurosurg Soc 45 : 16-23, 2009

18. Trout AT, Kallmes DF, Kaufmann TJ : New fractures after vertebroplasty : adjacent fractures occur significantly sooner. AJNR am J Neuroradiol 27 : 217-223, 2006

19. Tseung YY, Yang TC, Tu PH, Lo YL, Yang ST : Repeated and multiple new vertebral compression fractures after percutaneous transpedicular vertebroplasty. Spine (Phila Pa 1976) 34 : 1917-1922, 2009

20. Weng DHH, Jun HT, Chuen ST, Ming BTH, Hyh BLP, Hwan TK : Subsequent vertebral fractures post cement augmentation of the thoracolumbar spine. Spine (Phila Pa 1976) 40 : 1903-1909, 2015 